Madrygal. Revista de Estudios Gallegos

ISSN: 1138-9664

\title{
Unhas cantas observacións sobre a Antoloxía da nova poesía galega preparada e publicada por María Victoria Moreno no ano 1973
}

Xesús Alonso Montero ${ }^{1}$

\section{In memoriam}

Dedico este artigo a Fiz Vergara Vilariño (1953-1997), un dos escritores máis novos da Antoloxía de 1973, quen, anos despois, construíu unha obra poética rica, nobre, tensa e potente, expresión, ás veces, do seu terrible drama persoal. Na señardade, ¡Fiz!

\section{Nota preliminar}

No ano 1973, María Victoria Moreno Márquez publicou unha antoloxía da poesía galega, en edición bilingüe (galego-castelán), que, co paso do tempo, algúns lectores atentos cada vez valoran máis. Eu mesmo, tan vencellado á súa xestación, acabo de relela cun sentimento de admiración que, nesta medida, non tiven hai corenta e catro anos, data na que a nosa autora facía a súa primeira incursión, como estudosa, no eido das nosas Letras. Daquela, por certo, a antóloga foi obxecto dalgunhas críticas por privilexiar, na escolma, a poesía social. Neste traballo teremos ocasión de demostrar que tales críticas eran, obxectivamente, desaxeitadas. Eran críticas -cómpre aclaralo-que circulaban por certos faladoiros de café nos que predominaban letraferidos de ideario máis ou menos esteticista. Algunha vez, semellantes puntos de vista apareceron na prensa. É o caso da breve reseña asinada por T. en La Voz de Galicia (16/06/1974), que me estrañaría que fose Manuel Álvarez Torneiro. Opina o señor T.:

Si es cierto que abunda la riqueza expresiva en alguno de los autores, no son, precisamente, los valores creadores de poesía auténtica. La antología es, en líneas generales, de intención social, o cívica, con muy buenas ideas, por supuesto, pero creemos que una idea puesta en versos no es un poema si no la acompaña la otra fortuna.

Observamos unas notables diferencias en el conjunto de las composiciones, ya que al lado de versos felices, críticos e intencionados, nos encontramos con prosaicos discursos que pensamos no tienen nada que ver con una antología poética, por mucha denuncia social que los acompañe. Opinamos que la prosa es un vehículo más apto para este menester. La labor de la antóloga es, pese a todo, meritoria...

O contido social foi o que provocou que os gobernadores civís prohibisen -ou non autorizasen- a presentación da antoloxía. Hai unha moi significativa: a organizada no Mercantil de Santiago en marzo de 1974. Nesa ocasión o pretor provincial -segundo os xornais- non só prohibiu a presentación dos Novísimos senón tamén outros dous libros da colección Arealonga, Viaje por las escuelas de Galicia (1930), de Luis Bello, e Brujos y astrólogos de la Inquisición de Galicia..., de Bernardo Barreiro. De feito, o libro litixioso para o Gobernador era a antoloxía poética. Supoño que o señor gobernador ou os seus asesores sabían algo máis: que a colección Arealonga a dirixía un comunista chamado Xesús Alonso Montero e que a editorial, Akal, de Madrid, estaba ó servizo de "idearios disolventes". 


\section{Título, colección e nómina de poetas}

Titulouse Os novísimos da poesía galega / Los novísimos de la poesía gallega / Antología por..., e apareceu na colección Arealonga, de Akal Editor (Madrid), en 1973 (o prólogo ten data do 2 de agosto dese ano). Era o número 3 da colección que eu inaugurara, nese mesmo ano, co libro Informe -dramático- sobre la lengua gallega, libro moi polémico daquela (hoxe, infelizmente, non). A colección foi creada, bautizada e dirixida por min, dato que non é irrelevante para achegármonos a algúns aspectos da Antoloxía de María Victoria. En efecto, algún dos críticos chegou a pensar que María Victoria puxera o acento na poesía social porque estaba aconsellada ou condicionada polo "comunismo" de Alonso Montero.

Debo aclarar que nunca foi así, aínda que eu, director de Arealonga, algo tiven que ver na concepción da Antoloxía, e así o expresa na "Introducción" a propia antóloga:

El criterio establecido para la selección se basa en tres puntos:

- escribir en gallego

- tener un libro publicado

- haber nacido a partir de 1943

Está ben claro que non é discutible o primeiro punto, e, en canto ó segundo e ó terceiro, trátase de premisas moi razoables: que os poetas - da nova poesía, da novísima- non tivesen máis de trinta anos, e que fosen poetas cun certo estatus público, estatus conferido polo feito de teren publicado, como mínimo, un volume. Quedaban fóra, por tanto, os poetas novos só presentes, con algunhas composicións, en revistas e xornais. Curándose en saúde, María Victoria engadía esta observación:

Hubiese sido mi deseo dar entrada en estas páginas a todos los que reuniesen estas condiciones, pero las gestiones resultaron, a veces, infructuosas y me vi forzada, muy a pesar mío, a prescindir de figuras que gozan de toda mi admiración y simpatía.

Non sei a que poetas se refire María Victoria. Se alguén pensa en Arcadio López-Casanova (1942), xa superaba a idade acordada.

En canto ó título, ó que eu non fun alleo, pairaba sobre nós o dunha famosa antoloxía de Josep Maria Castellet titulada Nueve novísimos poetas (Barcelona, 1970). A de María Victoria, en función dos criterios, constituiuse con dez. Velaquí a relación, por orde cronolóxica: Farruco Sesto Novás (1943), Lois Diéguez (1944), Alfredo Conde Cid (1945), Xosé Vázquez Pintor (1946), Lois Álvarez Pousa (1948), Xesús Rábade Paredes (1949), Margarita Ledo Andión (1951), Darío Xohán Cabana (1952), Félix Vergara Vilariño (1953) e Xavier Rodríguez Barrio (1954).

\section{Características da Antoloxía}

Trátase dunha antoloxía consultada, ou sexa, entre a responsable do volume e cada un dos poetas escolleitos houbo un diálogo (ás veces epistolar), e ese fora o método, no seu día, de Gerardo Diego cando preparou Poesía española. Antología 1915-1931 (Madrid, Signo, 1932). É o método, grosso modo, que empregou en 1935-1936 Filgueira Valverde cando recolleu material para a súa Antoloxía consultada, inédita ata 2008, ano no que a publicaron Ana Acuña e Xesús Alonso Montero (Museo de Pontevedra et al.). Sendo esta a primeira antoloxía consultada da nosa poesía, a primeira que se publicou destas características é moi posterior, de 1955: a de Francisco Fernández del Riego, que titulou Escolma de poesía galega. Os contemporáneos (Vigo, Galaxia). Está claro que cando Del Riego elaborou esta Escolma non coñecía a de Filgueira Valverde, pero si a de Gerardo Diego, moi presente entre antólogos e estudosos. $\mathrm{Na}$ Antoloxía de María Victoria os textos dos autores van precedidos dunha autopoética, extensas algunhas, moi breves outras. Hainas con reflexións autobiográficas que, non carecendo de interese, moi pouco se porteñen co que entendemos por autoestética ou autopoética.

Vexamos como se pronuncian sobre a poesía social (así se chamaba na época) estes novísimos.

a) Farruco Sesto Novás é a voz superlativa do grupo, capaz de afirmar: "Yo creo en la poesía. Es decir, creo en esa poesía. Y estoy seguro que, de alguna manera, debe ser un instrumento de la lucha de clases y de que tiene un papel que cumplir, hoy por hoy, en el proceso de liberación de los pueblos y, más adelante, en la construcción de la nueva sociedad". E vai máis alá cando cita unhas liñas de Mato Tse Tung, sobre literatura e arte, proferidas polo líder comunista no Foro de Yenán: "No existe, en realidad, arte por el arte, ni arte que está por encima de las clases, ni arte que se desarrolle al margen de la política, o sea independiente de ella". 
Nunca, que eu lembre, este texto fora citado nun libro galego. Farruco Sesto Novás xa era un poeta de valía que foi medrando co tempo; era, obviamente, un cidadán de esquerdas naquela Venezuela gobernada polas dereitas. Desde hai tempo, está coa causa bolivariana, foi ministro con Hugo Chaves e segue a asumir moi importantes responsabilidades nesta hora, tan difícil.

b) Xesús Rábade Paredes non só se centra nos postulados do seu ideario socioestético, senón que constrúe un discurso moi do esquerdismo da época: "el capitalismo es fundamentalmente enemigo del arte"; "...el papel y la postura del hombre y del escritor gallego hoy es el papel y la postura de cualquier escritor honesto: estar con el pueblo, con la gente que vive con él. Ser fiel a los más duramente golpeados por la historia...".

c) Para Margarita Ledo "ser poeta hoy en Galicia" é "mezclarse con la fábrica, mezclarse con el mar y con la tierra, mezclarse con el sueño...". Pouco máis explicita nunha resposta breve e telegramática.

d) Darío Xohan Cabana cita, tamén, a Mao para matizar, con el, que a poesía social ha ter valores estéticos, pois se non os ten, non é revolucionaria. E conclúe: "No creo en la poesía social por la poesía social".

e) Félix Vergara Vilariño (aínda non se chamaba Fiz) fala moito da súa persoa, incluso das súas eivas físicas ("aspecto casi monstruoso") e, ó final, admite que "los poetas gallegos debemos fijar nuestro canto en unos hechos determinados, que no son precisamente la morriña y la saudade".

f) A estética "social" é mencionada -por ineludible naquela hora?- nas declaracións (máis que "autopoéticas") de: Alfredo Conde ("... la poesía en cada sitio debe ser testimonio de lo que ese sitio es”) e Vázquez Pintor (“...a mis versos, como a los zuecos, les gusta pisar la tierra y las piedras del camino que lleva a la fuente").

Non hai pronunciamentos substantivos en favor da poesía social nas declaracións de Lois Diéguez. Lois Álvarez Pousa e Xavier Rodríguez Barrio: nin substantivas nin adxectivas.

Capítulo curioso neste "decálogo" é o protagonizado por Lois Diéguez, autor dunha declaración moi breve (once liñas) na que, de feito, non se pronuncia como poeta civil pero ofrécenos un corpus de poesía social notorio: desde un canto que dedica "Ós labregos de Castrelo [de Miño]", cuxas terras van ser asolagadas polos "corvos" (a inmisericorde empresa FENOSA), ata un dos poemas máis cantados por Voces Ceibes, que titulou "Eu son a voz do pobo", maiúscula e ousada declaración de principios.

\section{A "Introducción" de María Victoria}

De catro partes consta este estudo introdutorio, escrito sempre con moita sinceridade e, en non poucas ocasións, cun xeito literario case poemático. Cada parte está presidida por un texto que, ó seu xeito, glosa a nosa autora.

I. Poema de León Felipe no que se proclama que o que cantan os poetas é unha canción composta para o vento, que, logo, só lembrará unhas cantas palabras, pero estas palabras

...son las que no olvidan nunca las piedras.

Lo que cuenta el poeta a las piedras está lleno [de eternidad

Y esta es la canción del destino, que tampoco [olvidan las estrellas.

María Victoria, que escolleu un texto moi especial -e moi ambicioso-, comeza a súa glosa con esta elevación:

Si tan sólo el viento es antólogo, si tan sólo su desmemoria está capacitada para discriminar lo efímero de lo eterno, no sé que hago yo aquí ni qué sentido tiene mi trabajo de leer, analizar, elegir o traducir versos.

Logo, interpelando ó vento do poema de León Felipe, proponnos esta interpretación:

El viento canta canciones eternas sobre un mundo angustiosamente finito. Y siempre desde arriba. Por eso, aunque sus canciones son hermosas, pueden no ser las que precisa oír el hombre concreto de un instante concreto. Podría decirse, de algún modo, que toda la poesía se divide en dos grandes grupos:

El primero estaría constituido por poemas atemporales, eternamente perfectos.

El segundo, por poemas temporales, vivamente imperfectos.

Corresponde al viento elegir los primeros, los de áureos destellos, los que siempre dirán algo al lector, y quizá nunca se lo dirán todo.

Corresponde al hombre elegir los segundos, los de vegetales fragancias, los que dirán todo al 
hombre de un tiempo y quizá no dirán nada al hombre de otro tiempo.

Sentado isto, confesa -e sínteo- "que alguna de las voces aquí recogidas enmudecerá (...) Pero estoy segura de que otras irán templándose en estos mismos obstáculos hasta adquirir los registros precisos para cantar un día su canción eterna, la que no olvidarán las estrellas" (expresión esta que lle rouba a un verso de León Felipe). Está claro que María Victoria, antóloga ó servizo duns criterios "obxectivos" (idade, libro publicado), non gusta dalgúns dos poetas antologados pero non ousa -nin era procedente- sinalalos.

II. "Luchar por los derechos de una lengua proletaria ha de entenderse como una lucha conjunta por los derechos todos del proletariado que la habla" (Xesús Alonso Montero). Son palabras miñas, coas ideas e a retórica "comunista" da época, dun traballo que María Victoria non cita. Quizais proceden do Informe, libro que a nosa autora reseñou no Diario de Pontevedra (15/09/1973). En cinco páxinas, a prologuista fai unha moi atinada historia do galego literario desde a óptica sociolingüística, pródiga en expresións acaídas e brillantes: "El gallego es, a lo largo de este período [XV-XIX], la lengua de un pueblo que calla más que habla"; "así pues, el hecho de escribir en gallego en 1973 significa, por lo menos, renunciar a la herencia que brinda el castellano..."; "Para ellos [os poetas], pues, la elección supone un compromiso de solidaridad con la lengua B y con la clase que la habla", etc.

III. "Galicia deitada e queda / transida de tristes herbas" (Federico García Lorca). Son os versos 11 e 12 do quinto dos Seis poemas galegos (1935) do gran poeta andaluz, escritor moi presente na vida intelectual de María Victoria (clases, conferencias, estudos...). Sobre este poemario de Lorca escribiu en 1985 un magnífico traballo por min solicitado, que estivo inédito ata o ano 2015, data na que o publicamos en Madrygal ( $\left.\mathrm{n}^{\circ} 18\right)$.

No esencial, a nosa autora aborda, neste terceiro capítulo do seu limiar, se os poetas antologados plaxian ou non a Celso Emilio Ferreiro. María Victoria recoñece que os poetas do libro, poetas sociais nun tempo no que xa non o son noutras latitudes, aquí cultivan esa poesía porque teñen a "fe que en otras partes se ha perdido". Os poetas - engade a autora- están atentos ó latexo da terra e do tempo, a "Galicia deitada e queda / transida de tristes herbas", que dixera o Mestre.

IV. Texto de Luis Cernuda que resume unha carta de Goethe a Schiller na que aquel lle fala dun poeta novo ó que aconsellou que escribise poemas curtos. O poeta, de 26 anos, co que se equivocou, terminaría sendo unha voz prodixiosa da poesía europea. Chamábase Hölderlin. Se Goethe, deus no Olimpo da época, se trabucou, María Victoria non quere pronunciarse sobre o futuro dos poetas da súa antoloxía, e opta por non dar nomes.

Non sei que pensaba María Victoria, trinta anos despois, da entidade e da cualidade dos poetas que antologara en 1973. Ata onde a coñezo, podo indicar que estaría moi satisfeita polos logros de Farruco Sesto Novás, Darío Xohán Cabana, Fiz Vergara Vilariño e Xesús Rábade Paredes, poeta -digámolo tamén- que se formou, no Lugo de 1965-1967, no seu colo profesional. Supoño que estimaría a valía poética de moitos poemas de Vázquez Pintor e Rodríguez Barrio.

\section{Da tradución}

María Victoria, que era filóloga e poeta, traballou con auténtico rigor as versións dos poemas antologados. Tamén nesta faceta do seu traballo contou coa colaboración dos autores dos poemas. Supoño que ningún deles se viu mal interpretado na versión castelá dos seus versos. O libro, representativo da poesía galega daquel momento (1973), chegou, mercé á tradución castelá de María Victoria, a ámbitos extragalegos pouco transitados polos nosos poetas. Neses ámbitos atopáronse co castelán coidado e medido de María Victoria Moreno Márquez, unha mediadora que xa non era unha escritora alófona, como García Lorca, unha mediadora que estaba instalada no idioma galego como se de lingua autófona se tratase.

En 1973, o ano desta utilísima antoloxía, María Victoria publicou, en galego, o seu primeiro libro de narrativa infantil, Mar adiante, que eu prologuei. Dous anos antes, ela, estremeña de nación, xa impartía (gratuitamente) clases de idioma galego a alumnos (voluntarios) de fala galega. As traducións dos Novísimos son obra de quen está instalada, radicalmente, nos dous idiomas. Era algo máis: unha filóloga e poeta que sempre procura a dimensión literaria dos versos, lonxe, moitas veces, da literalidade erudita. 